\title{
Quality management in surgery: improving clinical and surgical outcomes
}

\section{Gestão da qualidade em cirurgia: melhorando os resultados clínico-cirúrgicos}

Raphaella Paula Ferreira ${ }^{1}$; Phillipe Abreu, TCBC-PR ${ }^{1}$ id ; Flavio Daniel Saavedra Tomasich, TCBC-PR ${ }^{2}$; Vinicius Basso Preti, TCBC-PR².

\begin{abstract}
A B S T R A C T
Quality is a term used by various specialists, from different perspectives, having as a common point to identify focuses that promote their development in institutional management. Quality processes allow us to improve assistance, reducing complication and death rates and reducing costs. Currently, the positive experience of the patient is highly valued and should be sought by all institutions. The benefits of quality procedures are extensive. There is evidence of lower complication and mortality rates, cost reduction, uniformity of care, improved communication and opportunity for health education. There is a need for financial investment by the institutions, but they can be converted in the future. The idea that these are just bureaucratic steps must be fought because individualistic attitudes are no longer part of safe medicine. The success of a quality process requires interdisciplinarity, integration with quality offices for effective communication. The implementation of feasible attitudes should be sought, with a high adherence rate to seek patient satisfaction and safety. We will address historical aspects, the requirements for the implementation of a quality program, the concepts of indicators and the aspects that influence the quality in surgery, in addition to presenting benefits that such a program can offer to the surgeon and the institution.
\end{abstract}

Keywords: Quality Indicators, Health Care. Quality Management. Outcome Assessment, Health Care.

\section{INTRODUCTION}

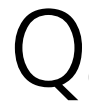
uality is a term used by various specialists, from different perspectives, having as a common point to identify focuses that promote their development in institutional management. The search for a unique concept becomes somewhat difficult, especially in the area of health. As quality management in health is organized, the benefit it generates for the client is evident ${ }^{1}$. For the World Health Organization, quality of care is the point at which the service offered to the patient and the population improves the expected results. To achieve the goal, care must be safe, effective, timely, efficient, equitable and people-centered ${ }^{2}$. The American Agency for Quality and
Health Research has defined it as doing the right thing for the right patient, at the right time, in the right way to obtain the best possible outcomes ${ }^{3}$.

There are several definitions of the term "quality" and all point to a common denominator for customer/patient safety and satisfaction. Quality processes improve care, reducing complication and death rates and reducing costs. Currently, the positive experience of the patient is highly valued and should be sought by all institutions.

We will address historical aspects, the requirements for the implementation of a quality program, the concepts of indicators and the aspects that influence the quality in surgery, besides presenting benefits that

1 - Faculdade de Ciências Médicas da Santa Casa de São Paulo, Departamento de Cirurgia, Área de Fígado e Hipertensão Portal - São Paulo - SP Brasil 2 -Hospital Erasto Gaertner, Departamento de Cirurgia, Serviço de Cirurgia Abdominal e Tórax - Curitiba - PR - Brasil 
a program like this can offer to the surgeon and the institution.

\section{HISTORY}

The theme quality is inherent to human evolution, it is a way of being constantly in search of improvement. The concern with quality started in the industry, as a way of survival of organizations ${ }^{4}$. One of the pioneers of quality was Walter A. Shewhart, who was named "father of statistical quality control". His work focused on improving the transmission of signals in the American telephone company "Bells Telephones". He also created the successive linear concept of steps for quality control in management: specification (determine how it should be done), production (actually do what was scheduled) and finally inspection (evaluate the result of the work done). His work influences managers in the search for excellence in management ${ }^{5}$.

A very important concept used by the industry was created by Kaoru Ishikawa, called "What is Total Quality Management? The Japanese Way". This concept, called Total Quality Management (TQM), advocated a constant environment of excellence to offer high quality products, focusing on customer satisfaction ${ }^{5}$. Figure 1 shows the flow chart of this quality process. At the same time, W. Edwards Deming, considered the "modern father of quality control", presented new concepts at a meeting of Japanese industry in 1950, called "Deming's cycle". This cycle is based on four points: product design, production, sales and customer satisfaction research ${ }^{5,6}$. After more than 70 years of industry guidelines for quality control, these concepts are extremely current.

In health, the focus of all attention is the patient, just as the customer is for the industry. If in the industry, in the concept of TQM, it is essential to involve the collaborator; in the area of healthcare, all the multidisciplinary team needs to be engaged and stimulated to achieve maximum quality and, consequently, safety for the patient (Figure 1).

The evaluation of quality in healthcare began in the 20th century through the American College of Surgeons, through the Hospital Standardization Program, created in 1924. It established the concept of attachment to the clinical staff and organization of the medical staff, the rules of mandatory completion of medical records, as well as discharge conditions. In 1948, the Hospital Standardization Manual was expanded. In 1951, the Joint Commission on Accreditation of Hospitals was created, which officially delegated the accreditation program to the Joint Commission on Accreditation of Hospitals in 1952. A "culture of quality" was introduced with emphasis on evaluation, education and health consulting. In addition, it helped establish laws in the area of health care ${ }^{7}$. Modern concepts of quality, with a focus on customer satisfaction as advocated by American and Japanese industry in the 1950's, began to be effectively instituted in the area of healthcare from 1970 onwards 4 .

In Brazil, a great step in quality was taken in 1998 by a joint initiative of the Brazilian College of Surgeons $(C B C)$, the Institute of Social Medicine of the State University of Rio de Janeiro (UERJ), the CESGRANRIO Foundation and the National Academy of Medicine (ANM). The Brazilian Consortium for Accreditation of Health Systems and Services was created with the objective of developing evaluations and quality improvement actions. It also included the participation of representatives of service providers, representatives of users, funders, health professionals and technicalscientific institutions ${ }^{1,8}$.

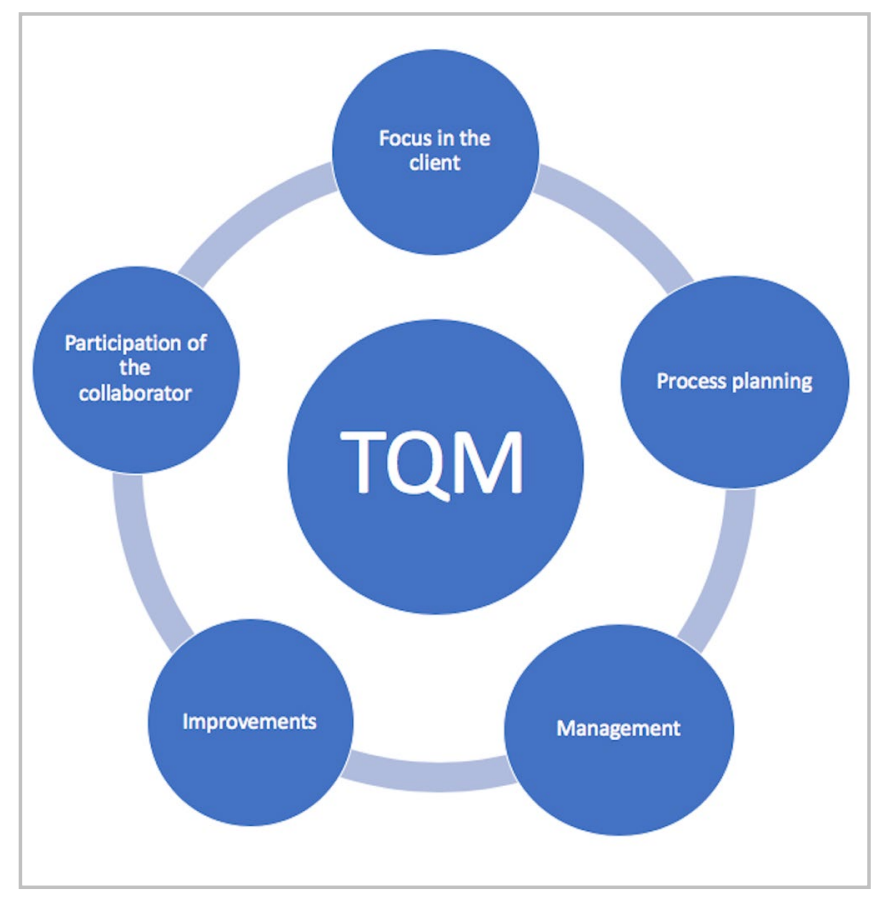

Figure 1. Total Quality Management (TQM) model focused on customer satisfaction. 


\section{Quality system implementation model}

The PDSA (Plan, Do, Study, Act) model has been adapted from general industry to the health area. It is based on the Deming's principles and is that applied by the NHS (National Health Service), the UK public health system. It is a tool for the development, measurement and implementation of changes aimed at improving the health system. These definitions are represented in Table 1. For the planning of the PDSA, three points need to be established: the objective, the measurement methodology and what changes are found that will result in improvement.

Table 1. PDSA management model definitions.

\begin{tabular}{ll}
\hline P (plan) & $\begin{array}{l}\text { Define the goal you want to achieve by } \\
\text { answering the questions: Who? What? } \\
\text { When? Where? Establish the data collec- } \\
\text { tion plan. }\end{array}$ \\
\hline $\mathrm{D}$ (do) & $\begin{array}{l}\text { Execute the plan, collect the data and start } \\
\text { the data analysis. }\end{array}$ \\
\hline $\mathrm{S}$ (study) & $\begin{array}{l}\text { Complete the analysis of the data collec- } \\
\text { ted and summarize the learning. }\end{array}$ \\
\hline A (act) & $\begin{array}{l}\text { Plan the next cycle and decide if the pro- } \\
\text { cess will be implemented. }\end{array}$ \\
\hline
\end{tabular}

Adapted from https://improvement.nhs.uk ${ }^{9}$.

Each institution has its own particularity, a type of service, a goal. The planning phase must take these items into consideration so that the actions are satisfactory. It is common for plans to change focus during their execution and require adaptation.

When starting a cycle it is common to find other suggestions or establish a new view, and the cycle can be restarted by noticing these changes, what is called sequential cycles. It is essential to understand the connection between cycles, to have a team engaged in the objectives and realization of plans. The clearer and more objective an action is, the greater the chance of accomplishing it successfully.

It is essential that all cycles are evaluated, their construction contemplated and demonstrated for the whole team. This leads to learning and a culture of constant improvement ${ }^{9}$. Whenever we have an engaged team, new suggestions for improvement emerge and quality service becomes a routine for the institution. Figure 2 demonstrates the proposed improvement model.

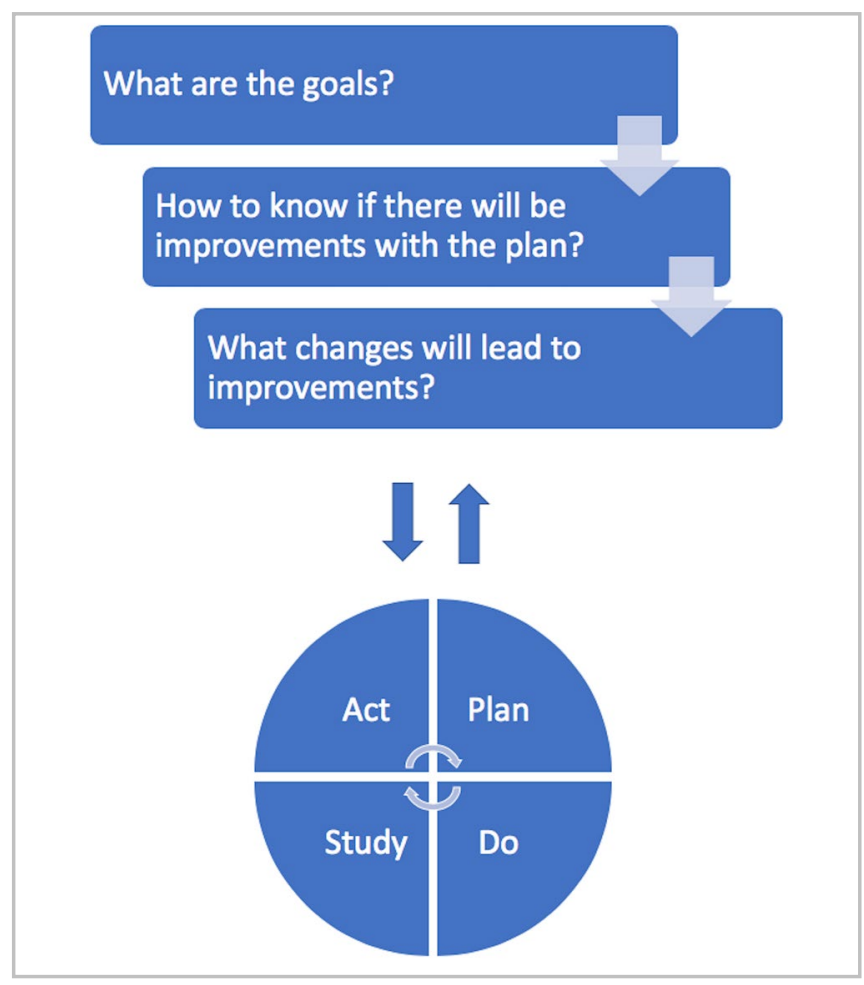

Figure 2. Improvement model using the PDSA method (Plan, Do, Study, Act).

\section{Indicators of quality in surgery}

The measurement of a quality process is carried out through indicators. They have the role of demonstrating the profile of the institution through numbers measured in time intervals, which makes it possible to direct the focuses of action and cycles of improvement. The quality indicators in surgery can be divided into 3 fields of approach: structural, process and outcomes.

\section{Structural indicators}

They include, among others, the hospital physical plant and equipment available for specific training of the surgeon ${ }^{10}$. A historical series showed that mortality is lower in hospitals with higher technology and more modern equipment in Intensive Care Units (ICU) ${ }^{11}$.

\section{Process indicators}

Process variables include patient care, such as the indication of vaccines or the use of betablockers in surgery in high-risk patients. The care offered in the preoperative 
period in a routine manner reflects the safety offered to patients. But these cares need to be routine, be part of a process $^{10}$.

\section{Outcomes indicators}

They reflect direct outcomes of surgical work, the most commonly used are surgical mortality rate, infection rates, hospital readmission, postoperative pneumonia, among others ${ }^{10}$. The National Surgical Quality Improvement Program (NSQIP), a quality program of the American College of Surgeons, started the systematic assessment of morbidity and mortality in hospitals of Veterans Affairs in the United States. This encouraged other hospitals in the country to do the same, emphasizing the importance of demonstrating the institution's outcomes for constant improvement ${ }^{12}$. Examples, advantages and disadvantages are specified in Table 2.

In the choice of indicators we must take into account 4 desirable characteristics ${ }^{13}$ :

1. Reliability and validity: the measurement must have internal and external validation and the results must be reproducible.

2. Low cost for data collection.

3. The measure must be accessible, i.e. at some point it must be possible to intervene to improve performance.

4. Objective defined.

The indicators are not static, as they are gauged and analyzed, it may be that one of them needs to be expanded or even removed from the analysis. Indicators that are difficult to measure can hinder the quality process.

\section{Quality in health care in Brazil}

In order to create indicators and establish an effective quality program, some concepts and guidelines must be followed according to the socio-economic reality of each region. In 2015, a network of research institutions was created (Health System Performance Evaluation Project - PROADESS) ${ }^{14}$, led by the Ministry of Health and the Oswaldo Cruz Foundation (Fiocruz), with the objective of establishing a performance evaluation methodology focused on the Brazilian health system. A matrix with quality attributes to characterize the performance of health services was defined, focusing on patient safety. These attributes are in Table 3.

The World Health Organization (WHO) also advocates patient safety, effectiveness and efficiency as quality goals. In addition, it is advocated that quality of care still offers ${ }^{15}$ :

1. Timeliness: reduce delays in the supply of healthcare.

2. Equity: health care cannot differ according to individual characteristics such as gender, race, geographic location and socioeconomic status.

3. Person-centered: the measures offered must take into account the individual preferences and aspirations and culture of the community.

All these characteristics must be taken into account when establishing a quality process in surgery. The cost-effectiveness, ease of information capture and implementation according to the characteristics of each institution should also be identified in order to allow the process to have greater adherence.

\section{Quality processes in surgery}

Specific items that should be taken into consideration, both for gauging and for implementing quality systems in surgery.

Failure-to-rescue concept

Surgical mortality was one of the first indicators to be evaluated in surgery, it represents the quality and safety offered by a surgical service. Failure-to-rescue is the death resulting from a postoperative complication within 30 days. It can also be defined as the lack of the ability to recognize and treat a surgical complication that leads to death. The presence of postoperative complications presents a heterogeneous spectrum of causes and treatments ${ }^{16,17}$ 
Table 2. Structural, process and outcome measures to assess quality in surgery.

\begin{tabular}{|c|c|c|c|}
\hline & Structural & Process & Outcomes \\
\hline \multirow[t]{3}{*}{ Examples } & Number of procedures & $\begin{array}{l}\text { Use of beta-blocker in high surgical risk } \\
\text { patients }\end{array}$ & Morbidity and mortality rates \\
\hline & Residency programs / & & Patient satisfaction \\
\hline & medical specialization & $\begin{array}{l}\text { Use of the internal mammary for coronary } \\
\text { artery bypass grafting }\end{array}$ & Cost \\
\hline \multirow[t]{2}{*}{ Advantages } & $\begin{array}{l}\text { Quick and inexpensive } \\
\text { measurement of } \\
\text { number of procedures }\end{array}$ & Reflects the care patients actually receive & $\begin{array}{l}\text { The measurements themselves } \\
\text { are a stimulus to the } \\
\text { improvement of results }\end{array}$ \\
\hline & & $\begin{array}{l}\text { Protocol adherence can be easily accessed } \\
\text { by management }\end{array}$ & \\
\hline Disadvantages & $\begin{array}{l}\text { Results are averages for } \\
\text { the entire group, with } \\
\text { limited identification of } \\
\text { individual problems }\end{array}$ & $\begin{array}{l}\text { Information lapse of which processes are } \\
\text { essential/ important for each specific } \\
\text { procedure }\end{array}$ & $\begin{array}{l}\text { Limiting the number of specific } \\
\text { procedures for significant } \\
\text { results }\end{array}$ \\
\hline
\end{tabular}

Table 3. Quality attributes.

\begin{tabular}{ll}
\hline \multicolumn{1}{c}{ Attribute } & \multicolumn{1}{c}{ Definition } \\
\hline Effectiveness & Degree to which assistance, services and actions achieve the expected results. \\
\hline Access & $\begin{array}{l}\text { Ability of the health system to provide the necessary care and service at the right } \\
\text { time in the right place. }\end{array}$ \\
\hline Efficiency & Relationship between the product of the health intervention and the resources used. \\
\hline Respect for people's rights & $\begin{array}{l}\text { Ability of the health system to ensure that services respect the individual and the } \\
\text { community, and are people-centered. }\end{array}$ \\
\hline Acceptability & $\begin{array}{l}\text { Degree to which the services offered are in accordance with the values and expecta- } \\
\text { tions of users and the population. }\end{array}$ \\
\hline Continuity & $\begin{array}{l}\text { Ability to provide services in an uninterrupted and coordinated manner between } \\
\text { different levels of attention. }\end{array}$ \\
\hline Suitability & $\begin{array}{l}\text { The degree to which the care provided to people is based on existing well-founded } \\
\text { technical-scientific knowledge. }\end{array}$ \\
\hline Security & $\begin{array}{l}\text { Ability of health systems to identify, avoid or minimise potential risks from health } \\
\text { and environmental interventions. }\end{array}$ \\
\hline
\end{tabular}

Table available at: PROADESS- Evaluation of the Brazilian health system performance: indicators for monitoring. Rio de Janeiro, $2011^{14}$.

Usually a single complication proceeds from the other events, and should be viewed as a sentinel event, which occurs on average between 5 and 10 days prior to death, and early intervention can reduce death rates $^{18}$. This reflects the quality of care provided and several factors are involved in the lack of recognition of this sentinel event.

One of the ways to identify the patients with the 
highest chance of complication is their risk stratification. The American College of Surgeons has developed the NSQIP through the quality improvement program. It is a tool in which 21 variables are analyzed to establish the risk of complications and mortality ${ }^{19}$. This tool, validated in 2017, allows the surgeon to discuss with the patient and family the probability of risk compared to the expected mean, make pre-procedural decisions, share decision-making processes, clarify expectations and even contraindicate the procedure if needed ${ }^{20}$.

One study, which used this tool, showed that $90 \%$ of the surgical complications occurred in a specific group of higher risk, which corresponds to $20 \%$ of all patients, that is, we can recognize who are the patients with higher risk for negative outcomes. This is similar to the Pareto Principle, used in the economic field, in which $20 \%$ of the individuals are responsible for $80 \%$ of the results. By focusing on the line of care for this group with greater propensity to develop postoperative complications, we can reduce surgical mortality rates ${ }^{18}$.

\section{Factors that influence surgical complications}

Hospital: the differences in mortality between hospitals can be explained through the concept of "failure-to-rescue"16,17. One of the largest series of postoperative complications analysis, which evaluated 1,956,002 patients, hospitals were divided into 5 groups of similar hospitals, according to the rate of complications. The study showed that $88 \%$ of complications occurred in a specific group ${ }^{18}$. The way complications are conducted or the recognition of complications is what caused this difference.

Co-managed care: a general practitioner or internal medicine specialist can assist in postoperative care, allowing the surgeon to devote himself to specific activities. This type of work consists of evaluation performed in a horizontal manner, in which decisions are shared, in contrast to those taken to solve specific problems ${ }^{21}$. A series of a single 857-bed institution showed that the presence of an internist hospital doctor reduced the postoperative mortality rate and the total time of hospitalization ${ }^{22}$.

Medical residency programs: although the presence of resident physicians can be expected to increase complication rates, their presence has reduced the "failure-to-rescue" rate when compared to the care of the attending surgeon alone. This occurred despite longer surgical time, in a series that evaluated almost 2 million patients ${ }^{18}$. Bedside discussions between surgeons and residents may lead to better care and explains this type of outcome ${ }^{17}$.

Other factors may be involved in the mortality rate, such as the number of nurses per patient, number of hospital beds and presence of certified intensivists ${ }^{23}$. Although these factors cannot be directly modified by the surgeon, it is important to recognize them to discuss improvements with the administration.

Non-modifiable factors: in the United States, it has been demonstrated that patients with low socioeconomic level present higher rates of postoperative complications. This is a non-modifiable factor, with no effectiveness of any type of preoperative intervention. However, based on the recognition of this type of factor, the patient should be considered as having a higher potential for postoperative complications and make the team aware of this possibility ${ }^{17}$.

How to reduce mortality in surgery

By recognizing the factors that lead to mortality, a model was proposed to reduce such an outcome. Usually complications that culminate in death start in an isolated event also called a seminal event. When this is not recognized, cascading events may occur, culminating in death, as demonstrated in Figure 3. Training to recognize it is one of the key pieces in preventing mortality, but not only this, but also in treating it, preventing the seminal event from evolving into cascade events. Nursing is the front line and whoever spends more time in contact with the patient and the training destined to it is essential in recognizing the sentinel event ${ }^{17}$. For example, the nursing team trained to promptly recognize a hypoxic patient as a sentinel event, and to have fast and effective communication with the surgeon, can prevent progression to cascade events ${ }^{23}$.

Prevention programs are also effective for reducing the incidence of sentinel events. A study called Keystone Initiative, showed effectiveness in reducing the incidence of central venous catheter infection, 
reducing the rate of sepsis ${ }^{24}$. Another study showed that adherence to protocols for prevention of sepsis, showed a decrease in mortality and length of stay in the ICU 25 . Recognition of the sentinel event is the pillar, but if there is no communication and teamwork culture, taking action may not be effective. Therefore, according to the Figure 3, training, investments in quality, leadership stimulus and quick response teams allow the team to act quickly and effectively, preventing the final death event.

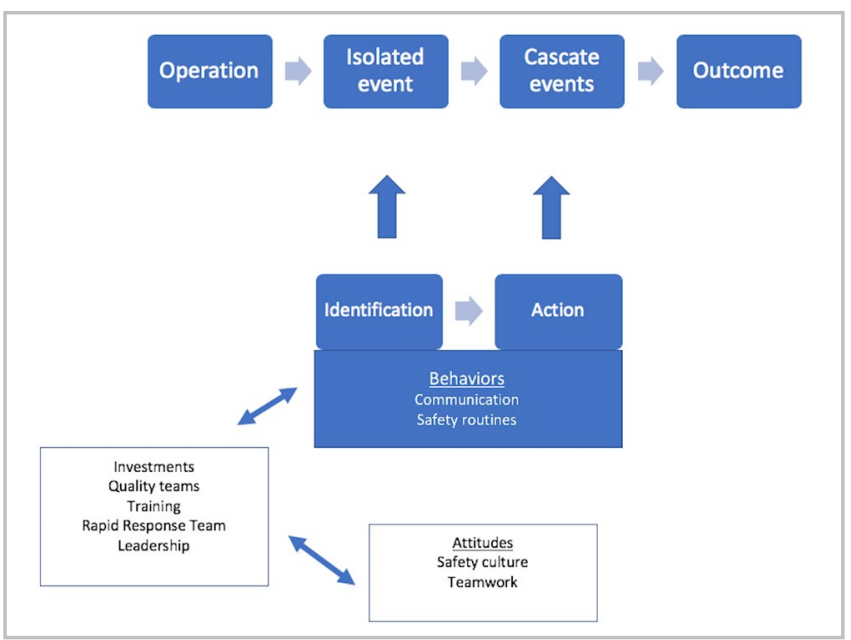

Figure 3. Recognition of the sentinel event and teamwork to prevent surgical mortality.

Safe surgery as a quality tool

The safe surgery checklist is one of the most widely used tools in the world for reducing adverse events and is an indicator of quality of patient care. After some years of research, in 2009 the WHO released the safe surgery checklist as part of the "Safe Surgery Saves Lives" program. The proposal of the implantation is to evidence to the teams that important steps for patient safety should be remembered and verified preventing the occurrence of adverse events. In addition, this protocol provides improved communication and teamwork ${ }^{26}$. In Brazil, the Brazilian College of Surgeons has published the Safe Surgery Manual and stimulates its implantation in order to minimize complications and mortality related to surgical procedures ${ }^{27}$.

A prospective multicenter series, involving 8 hospitals around the world, was the study that highlighted the benefits that a safe surgery checklist can offer. Several studies followed the implementation of the protocol after its publication. When establishing the WHO's "Safe Surgery Saves Lives" program, it found that the mortality rate reduced from $1.5 \%$ to $0.8 \%$ and the rates of surgical complications reduced from 11 to $7 \%$. There was also a reduction in the operative wound infection rate and in the number of emergency re-operations. All these changes were identified in all hospitals, despite the clinical and economic characteristics of each region ${ }^{28}$. Since its implementation and dissemination, several studies have demonstrated the efficacy, showing a reduction in mortality and complications, offering better quality services to patients. A large Italian series, which surveyed the results in more than 1 million patients undergoing surgery, evaluated in 48 different public hospitals, showed that hospitals with high adherence to the checklist (more than $75 \%$ ) had lower readmission rate and shorter inhospital stay. However, the reduction in mortality rate showed no difference. Part of the data may be due to the large variation in the checklist adherence rate, which varied from 0 to $93 \%{ }^{29}$. Another institution showed a reduction in the morbidity rate, especially the incidence of surgical site infection and thrombo-embolic events. The use of the checklist was an independent factor of better postoperative outcomes ${ }^{30}$.

Despite the benefits, there may be barriers to the implementation of the protocol. The Italian study with more than 1 million surgeries analyzed showed that in some centers there was no adherence to the protocol $^{29}$. In Brazil, in a single institution, adherence to the safe surgery protocol was $58.5 \%$, a lower result than international centers. This group was one of the pioneers in the implementation of the protocol and presented data followed over 5 years. Adherence to the protocol was higher in surgeries during the day and on working days. Even the hiring of a specific professional to fill out the checklist was not efficient enough in improving adherence to it. The study suggests that the culture of safe surgery should be part of the institutional planning and tools such as feedback on data completion and awareness of the importance of the checklist can enhance the entire process quality ${ }^{31}$. Other strategies to increase adherence is to stimulate educational programs about the importance of it, leadership programs to apply the protocol and involve the patient. The checklist, in 
phases where the patient is not under anesthetic effect, should involve him/her. There is evidence of greater satisfaction when this measure is taken ${ }^{32}$.

One of the tools for recognizing adverse events and complications at an early stage is communication between the different teams. Another Brazilian group applied a pre and post implementation questionnaire of the safe surgery checklist to assess the perception of assistant teams regarding safety in surgery. Most professionals reported improved communication after implementation of the safe surgery checklist, with these rates being $92.7 \%$ for nursing staff, $87.9 \%$ for anesthesiologists, and $75.6 \%$ for surgeons. All professionals also believed that the checklist reduces the rate of adverse events in the operating room and improves the culture of safety in surgery, but the lowest rates on these issues were for surgeons ${ }^{33}$.

\section{Multimodal protocols in surgery}

The multimodal protocols aimed at postoperative recovery emerged to translate the subjectivity of medical conduct. Many medical decisions are based on knowledge acquired from other generations of doctors, also recognized as "experience" or "common sense". But in evidence-based medicine, this is the lowest degree of recommendation. Two major multimodal protocols in surgery, Enhanced Recovery After Surgery (ERAS), originated in Europe, and ACEleração da REcuperação TOtal pós-operatória (ACERTO), from Brazil, are examples of the difference that a protocol offers in terms of improvement in outcomes ${ }^{34,35}$.

The ACERTO project brought to the national reality some conducts such as early postoperative refeeding, ultra-early mobilization, perioperative nutritional support, use of epidural catheter for analgesia, among other conducts. Among the benefits of the protocol, an increase in the number of surgeries without an increase in the number of hospital beds was identified in the first hospital where it was instituted. This was a result of earlier discharge with higher bed turnover. Mortality was reduced over the years after the implantation of the program. This reflects an improvement in the quality offered to the patient, with the possibility of more satisfactory outcomes ${ }^{35}$.
The ERAS protocol, which was initiated with colorectal surgery, has been presenting more and more positive results. It has been extended to gynecological, oncological, bariatric and pediatric surgery among other specialties. A recent review showed a reduction in length of stay, postoperative complications rates and impact on costs. There is also a reduction in severe complications, with a reduction in the ICU readmission rate ${ }^{36}$.

The multimodal protocols have proven to be an excellent option for patient safety and in reducing postoperative complications and their implementation in surgical services is recommended.

\section{Audit in surgery}

One of the pillars of the ACERTO project is the audit in surgery. First of all, through the serial audit we are able to highlight the improvements implemented. The reduction of mortality from 3.5 to $1 \%$ was only possible due to the audit. The second approach that the serial audit offers is the need for actions when there is a drop in the indicators. For example, the adherence to abbreviated preoperative fasting in 2009 was $72 \%$, but there was a drop to $65 \%$ in 2013 . By emphasizing this reduction, actions were taken and the index rose to $86.6 \%$ the following year ${ }^{35}$.

The constant evaluation of goals and guidelines guides the need for health education and training, and is a dynamic process that should always be valued. Serial assessment of indicators with critical analysis is fundamental for effective implementation.

\section{Operative pre-habilitation}

The "failure-to-rescue" is an important tool because it allows the reduction of postoperative mortality. It is designed for early identification and correction of complications in the preoperative period. But there are measures that can be instituted in the preoperative period to reduce complications and offer a better quality and safer recovery for patients, called operative prehabilitation. This is a relatively new concept, but it can provide better postoperative outcomes and should be stimulated to be part of the routine quality of surgical services. 
Pre-habilitation aims expanding the functional and psychological capacity of the patient. It involves several factors, such as programmed physical activity, nutritional therapy, smoking cessation, psychological well-being, correction of anemia and control of comorbidities $^{37}$. A randomized series, involving patients over 70 years old and classified as ASA III or IV, showed that there was a $51 \%$ reduction in complications in those patients undergoing pre-habilitation ${ }^{38}$. On the other hand, smoking interruption, between 6 and 8 weeks prior to surgery, is effective to reduce operative complications, especially those related to surgical incisions healing ${ }^{39}$. A systematic review on the performance of preoperative physical exercises in patients with cancer showed that there was improvement in postoperative outcomes in abdominal surgeries. There was great variation in the type, duration and intensity of physical exercises and although the nutritional preparation was not evaluated, the authors advocated physical exercise to improve postoperative outcomes ${ }^{40}$. Another systematic review on physical exercises aimed at strengthening the respiratory muscles, aerobic activity and resistance showed a reduction in the rate of postoperative complications, including pulmonary complications. However, there was no benefit in length of stay and mortality ${ }^{41}$. For patients with neoplasia, pre-habilitation should be initiated at the time of diagnosis. These patients, due to the need for treatment for the neoplasia, may not have enough time to perform the entire program. For those who will be submitted to neoadjuvant treatment, this interval until surgery is a great opportunity to perform this type of intervention. The focus is no longer only on rehabilitation after treatment, but also on previous interventions ${ }^{42}$.

The evidence demonstrates the effectiveness of preoperative qualification and there is no doubt that its implementation is capable of offering greater quality, safety and patient satisfaction, since there is faster recovery of preoperative functional capacity.

\section{The surgeon facing quality}

A frequent paradigm among doctors, especially surgeons, is: "I am a conscious and competent doctor. Why do I need a quality system?" This mentality is flawed, since the health activity is no longer focused on the individual activity of a doctor's office in the mid-20th century, but on the work of a multidisciplinary team. Unfortunately, this individualistic perception can still be found as medical behavior, which results in varying levels of patient care. Instead, health care should be seen as a process that encompasses several specialists and a multidisciplinary team, aiming at a uniformity of care. And as a final objective, it aims to maximize the effectiveness and efficiency of the services offered ${ }^{5}$. When the collaborator or in the case, the surgeon, is involved and aware of the systemic vision of the work and quality processes, he will act in order to stimulate integration among people. Therefore, there is a greater chance of professional satisfaction and positive return in the sustainability aspects of the institution'.

The surgeon has a leading role and needs to be encouraged to notify and identify failures in patient care. In a Brazilian study, surgeons identified that 52\% of surgical failures were registered in their hospitals. They also reported that $35.3 \%$ of them have had more than 2 adverse events related to surgery. However, more than $20 \%$ of the surgeons interviewed still refuse to apply the safe surgery checklist to their teams ${ }^{43}$.

\section{Quality and the financial aspect}

A study of almost 1.5 million patients evaluated several American hospitals in two distinct periods: the first 2003-2004 and the second between 2009-2010. The hospitals were divided into five percentiles according to improvement in quality performance. Among the 20\% of hospitals that reduced the most complications, the reduction in costs per patient was over 1,500 dollars. On the other hand, those hospitals that remained in the last percentile of reduction of complications, the cost per patient increased ${ }^{44}$. The Keystone Initiative study established a checklist and guidelines to reduce the rate of central venous catheter infection, reduced by more than $66 \%$ over 18 months, showing the effectiveness of a quality protocol. In the United States, where the study was conducted, the estimated average cost of a central catheter infection is 45 thousand dollars per patient ${ }^{24}$.

There is no doubt that in order to have a financial return with quality improvements there is a need for investment. This can make the cost of promoting quality worrisome to the hospital manager. In the United States, 
for the same Keystone Initiative study, the estimated annual cost of implementing the program was close to 160 thousand dollars per hospital. Considering catheterrelated infections and ventilator-associated pneumonia, the difference between investment and expenditures is close to $\$ 1.1$ million per hospital, evidencing the financial benefit of a quality program ${ }^{45}$.

No matter how costly and, possibly resilient, implementing a quality system may be, the long-term benefit is financially evident.

\section{Opportunities for improvement with quali- ty programs in surgery}

By establishing quality plans and delimiting which indicators should be used, during data collection we can identify points of weakness that lead to an intervention. Every point of weakness must be addressed and a new cycle proposed. A Brazilian study, when evaluating the quality of care for trauma victims by relating trauma severity indexes to the chance of death, showed that most cases (approximately 77\%) could not be evaluated. This was attributed to two factors: lack of assistance by the trauma team and the non-availability of the medical records. The authors themselves reported that after computerization there was no more loss of medical records. When proposing to collect a quality of care data, it was possible to identify a fragility of the hospital information system and an improvement was installed ${ }^{46}$. As simple or evident as the problem is, such as the lack of medical records, the data collection makes it evident to the entire team. Transparency in the identification of data should always be encouraged, because from this, we are able to improve.

\section{CONCLUSION}

The benefits of quality procedures are extensive. There is evidence of lower complication and mortality rates, reduced costs, uniformity of care, improved communication and opportunity for health education. There is a need for financial investment by institutions, but these can be converted in the future profit. The idea that these are just bureaucratic steps must be fought because individualistic attitudes are no longer part of safe medicine. The success of a quality process requires interdisciplinarity, integration with quality offices for effective communication. The implementation of feasible attitudes should be sought, with a high adherence rate to seek patient satisfaction and safety.

\title{
R E S U M O
}

\begin{abstract}
Qualidade é um termo utilizado por diversos especialistas, sob diferentes perspectivas, tendo como ponto comum identificar focos que promovam seu desenvolvimento na gestão institucional. Os processos de qualidade permitem melhorias na assistência, reduzindo taxas de complicações e óbitos e reduzindo os custos. Outros benefícios dos procedimentos de qualidade são a uniformidade do atendimento, a melhoria na comunicação e a oportunidade de educação em saúde. Gerando uma experiência positiva do paciente que é altamente valorizada e deve ser buscada por todas as instituições. Há necessidade de investimento financeiro por parte das instituições, mas que será revertida futuramente. A ideia de que são apenas passos burocráticos deve ser combatida, pois atitudes individualistas já não fazem mais parte de uma medicina segura. Para o sucesso de um processo de qualidade é necessária interdisciplinaridade, integração com os escritórios da qualidade para uma comunicação efetiva. Deve-se buscar a implementação de atitudes factíveis, com alta taxa de aderência para buscar a satisfação e segurança do paciente. Abordaremos aspectos históricos, os requisitos para a implementação de um programa de qualidade, os conceitos de indicadores e os aspectos que influenciam a qualidade em cirurgia, além de apresentar benefícios que um programa como este pode oferecer ao cirurgião e à instituição.
\end{abstract}

Palavras chave: Indicadores de Qualidade em Assistência à Saúde. Gestão da Qualidade. Avaliação de Processos e Resultados em Cuidados de Saúde.

\section{REFERENCES}

1. Bonato VL. Gestão de qualidade em saúde: melhorando a assistência ao cliente. O Mundo da
Saúde, São Paulo: 2011;35(5):319-31.

2. World Health Organization. What is quality of care and why is it important? Geneva: WHO [acessado em 7 abril de 2020]. Disponível em: https://who.int. 
3. Agency for Healthcare Research and Quality. U.S. Department of Health and Human Services. Diabetes care quality improvement: A resource guide for state action. Disponível em: https://archive. ahrq.gov/professionals/quality-patient-safety/ quality-resources/tools/diabguide/diabqguide.pdf. Acessado em: 04 abr 2020.

4. Waitzberg DL. Nutrição oral, enteral e parenteral na prática clínica. 5a ed. Rio de Janeiro: Atheneu; 2017.

5. Yuan F, Chung KC. Defining quality in health care and measuring quality in surgery. Plast Reconstr Surg. 2016;137(5):1635-44.

6. Business901. Evolution of the PDCA Cycle. Fort Wayne: Business901; 2014 [acessado 07 de abril de 2020]. Disponível em: http://business901.

7. Feldman LB, Gatto MAF, Cunha ICKO. História da evolução da qualidade hospitalar: dos padrões a acreditação. Acta Paul Enferm. 2005;18(2):213-9.

8. Colégio Brasileiro de Cirurgiões [Internet]. Disponível em: https:/www.cbc.org.br, acessado em 13 de abril de 2020.

9. NHS. Quality, Service Improvement and Redesign Tools: Plan, Do, Study, Act (PDSA) cycles and the model for improvement. Disponível em https:// improvement.nhs.uk, acessado em 10 de abril de 2020.

10. Birkmeyer JD, Dimick JB, Birkmeyer NJ. Measuring the quality of surgical care: structure, process, or outcomes? J Am Coll Surg. 2004;198(4):626-32.

11. Daley J, Forbes MG, Young GJ, Charns MP, Gibbs JO, Hur K, et al. Validating risk-adjusted surgical outcomes: site visit assessment of process and structure. National VA Surgical Risk Study. J Am Coll Surg. 1997;185(4):341-51.

12. Fink AS, Campbell DA Jr, Mentzer RM Jr, Henderson WG, Daley J, Bannister J, et al. The National Surgical Quality Improvement in non-veterans administration hospitals: initial demonstration and feasibility. Ann Surg. 2002;236(3):344-53.

13. Morrow M, Katz SJ. The challenge of developing quality measures for breast cancer surgery. JAMA. 2012;307(5):509-10.

14. PROADESS - Avaliação de desempenho do sistema de saúde brasileiro: indicadores para monitoramento. Rio de Janeiro: FIOCRUZ; 2011 [acessado em 08 de abril de 2020]. Disponível em: https://www.proadess. icict.fiocruz.br/SGDP-RELATORIO_FINAL\%20_com_ sumario_atualizadorev\%202014.pdf

15. Organização Mundial de Saúde. Disponível em: https://www.who.int/, acessado em 15 de junho de 2020.

16. Farjah F. Failure-to-rescue in thoracic surgery. Thorac Surg Clin. 2017;27(3):257-66

17. Portuondo Jl, Shah SR, Singh H, Massarweh NN. Failure to Rescue as a Surgical Quality Indicator: Current Concepts and Future Directions for Improving Surgical Outcomes. Anesthesiology. 2019;131(2):426-37.

18. Ferraris VA, Bolanos M, Martin JT, Mahan A, Saha SP. Identification of patients with postoperative complications who are at risk for failure to rescue. JAMA Surg. 2014;149(11):1103-8.

19. Bilimoria KY, Liu Y, Paruch JL, Zhou L, Kmiecik TE, Ko $C Y$, et al. Development and evaluation of the universal ACS NSQIP signal risk calculator: a decision aid and informed consent tool for patients and surgeons. J Am Coll Surg. 2013;217(5):833-42.e1-3.

20. Cohen ME, Liu Y, Ko CY, Hall BL. An examination of American College of Surgeons NSQIP surgical risk calculator accuracy. J Am Coll Surg. 2017;224(5):78795.e1.

21. Whinney C, Michota F. Surgical comanagement: a natural evolution of hospitalist practice. J Hosp Med. 2008;3(5):394-7.

22. Hinami K, Feinglass J, Ferranti DE, Williams MV. Potential role of comanagement in "rescue" of surgical patients. Am J Manag Care. 2011;17(9):e3339.

23. Ghaferi AA, Dimick JB. Variation in mortality after high-risk cancer surgery: failure to rescue. Surg Oncol Clin N Am. 2012;21(3):389-95.

24. Pronovost $P$, Needham D, Berenholtz S, Sinopoli $\mathrm{D}$, Chu $\mathrm{H}$, Cosgrove $\mathrm{S}$, et al. An interventional to decrease catheter-related bloodstream infections in UCI. N Engl Med. 2006; 355(26):2725-32.

25. Zambon M, Ceola M, Almeida-de-Castro R, Gullo A, Vicent JL. Implementation of the SurvivingSepsis Campaign guidelines for severe sepsis and septic shock: we could go faster. J Crit Care. 2008;23(4):455-60. 
26. World Alliance for Patient Safety. WHO guidelines for safe surgery 2009: Safe surgery saves lives. Geneva: World Health Organization; 2009.

27. Colégio Brasileiro de Cirurgiões. Manual de Cirurgia Segura [Internet]. 2015 [acesso em 07 de maio de 2020]. Disponível em: https://cbc.org.br/wp-content/ uploads/2015/12/Manual-Cirurgia-Segura.pdf.

28. Haynes AB, Weiser TG, Berry WR, Lipsitz SR, Breizat $A H$, Dellinger EP, Herbosa $T$, Joseph $S$, Kibatala PL, Lapitan MC, Merry AF, Moorthy K, Reznick RK, Taylor B, Gawande AA; Safe Surgery Saves Lives Study Group. A surgical safety checklist to reduce morbidity and mortality in a global population. $\mathrm{N}$ Engl J Med. 2009;360(5):491-9.

29. Rodella S, Mall S, Marino M, Turci G, Gambale G, Montella, MT, et al. Effects on Clinical Outcomes of a 5-Year Surgical Safety Checklist Implementation Experience: A Large-scale Population-Based Difference-in-Differences Study. Health Serv Insights. 2018;11: 1178632918785127.

30. Hao W, Taohua Z, Dong C, Zhaojian N, Xiaobin Z, Shikuan $\mathrm{L}$, et al. Impacts of the surgical safety checklist on postoperative clinical outcomes in gastrointestinal tumor patients. A single-center cohort study. Medicine (Baltimore). 2019;98(28):e16418.

31. Ribeiro HCTC, Quites HFO, Bredes AC, Sousa KADS, Alves M. [Adherence to completion of the safe surgery checklist]. Cad Saude Publica. 2017;33(10):e00046216. Portuguese.

32. Papadakis M, Meiwandi A, Grzybowski A. The WHO safer surgery checklist time out procedure revisited: Strategies to optimise compliance and safety. Int J Surg. 2019;69:19-22.

33. Santana HT, Rodrigues MCS, Evangelista MSN. Surgical teams' attitudes and opinions towards the safety of surgical procedures in public hospitals in the Brazilian Federal District. BMC Res Notes. 2016;9:276.

34. Fearon $K C$, Ljungqvist $O$, Von Meyenfeldt $M$, Revhaug A, Dejong CHC, Lassen K, et al. Enhanced recovery after surgery: a consensus review of clinical care for patients undergoing colonic resection. Clin Nutr. 2005;24(3):466-77.

35. Aguilar-Nascimento JE. Acerto: acelerando a recuperação total pós-operatória. 3a ed. Rio de
Janeiro. Rubio; 2016.

36. Ljungqvist $O$, Scott $M$, Fearon KC. Enhance Recovery after surgery. A review. AMA Surg. 2017;152(3):2928.

37. Gonçalves CG, Groth AK. Pré-habilitação: como preparar nossos pacientes para cirurgias abdominais eletivas de maior porte? Rev Col Bras Cir. 2019;46(5):e20192267.

38. Barberan-Garcia A, Ubre M, Roca J, Lacy AM, Burgos F, Risco R, et al. Personalised prehabilitation in highrisk patients undergoing elective major abdominal surgery: a randomized blinded controlled trial. Ann Surg. 2018;267(1):50-6.

39. Gustafsson UO, Scott MJ, Hubner M, Nygren J, Demartines N, Francis N, et al. Guidelines for Perioperative Care in Elective Colorectal Surgery: Enhanced Recovery After Surgery (ERAS $®$ ) Society Recommendations: 2018. World J Surg. 2019:43(3):659-95.

40. Thomas G, Tahir MR, Bongers BC, Kallen VL, Slooter $G D$, van Meeteren N. Prehabilitation before major intra-abdominal cancer surgery. A systematic review of randomised controlled trials. Eur J Anaesthesiol. 2019;36(12):933-45.

41. Moran J, Guinan E, McCormick P, Larkin J, Mockler $D$, Hussey J, et al. the ability of prehabilitation to influence postoperative outcome after intraabdominal operation: a systematic review and metaanalysis. Surgery. 2016;160(05):1189-201.

42. Fong ZV, Chang DC, Keith D, Lillemoe KD, Nipp RD, Tanabe KK, et al. Contemporary Opportunity for Prehabilitation as Part of an Enhanced Recovery after Surgery Pathway in Colorectal Surgery. Clin Colon Rectal Surg. 2019;32(2):95-101.

43. Correia MITD, Tomasich FDS, de-Castro Filho HF, Portari Filho PE, Colleoni Neto R. Segurança e qualidade em cirurgia: a percepção de cirurgiões no Brasil. Rev Col Bras Cir. 2019;46(4):e2146.

44. Scally CP, Thumma JR, Birkmeyer JD, Dimick JB. Impact of surgical quality improvement on payments in medicare patients. Ann Surg. 2015;262(2):24952.

45. Waters HR, Korn R Jr, Colantuoni E, Berenholtz SM, Goeschel CA, Needham DM, et al. The business case for quality: economic analysis of the Michigan 
Keystone Patient safety program in ICUs. Am J Med Qual. 2011;26(5):333-9.

46. Costa CDS, Scarpelini S. Evaluation of the quality of trauma care service through the study of deaths in a tertiary hospital. Rev Col Bras Cir. 2012;39(4):24954.

Received in: 13/07/2020

Mailing address:

Accepted for publication: 05/08/2020

Vinicius Basso Preti

Conflict of interest: no.

E-mail: vbpreti@me.com

Funding source: none. 